\title{
Resilience in the Gaze of Ebola: Analysis from a Developing Country
}

\author{
Matthew Waritay Guah \\ South Carolina State University \\ mguah@scsu.edu
}

\begin{abstract}
Many studies have looked at resilience during natural disasters and national emergencies in a number of countries but hardly any have concentrated on developing countries and the implications of these nations' sub-standard healthcare infrastructure, culture practices and relaxed control systems. This paper examines resilience during Liberia's recent EBOLA epidemic and identifies lessons to be learned by others including executives of Non-Governmental Organizations frequently working on disaster relief projects in developing countries. The author builds on existing bodies of work and presents arguments on why governments in developing countries dealing with disaster management and disease emergencies should encourage communities to innovate autonomously as an important pathway to resilience. While the author does not provide specific recommendations, the paper proposes an approach that can connect the concerns of those implementing resilience initiatives and vulnerable populations by harnessing their potential for innovating autonomously.
\end{abstract}

\section{Introduction}

As Liberians confronted Ebola outbreak (March 2014 -- December 2015) and global observers grappled with preventing its widespread, the local people demonstrated resilience by preserving the social culture of handshakes and customary burial ceremonies. Unable to predict the new society in post-Ebola Liberia, community leaders were sufficiently resilient in buttressing a pretty good set of drivers to shape future public health practices and influence decisions about implementing a robust health system of international standards [29].

WHO defines a health system as one designed to coordinate all the activities required to promote, restore and/or maintain health of individuals and populations [29]. Inadequacy of healthcare systems in Liberia, facilitated the ease with which Ebola spread from one village in Guinea to threaten the lives of every resident and over 11,000 deaths within a 2years period [3]. Despite Liberia's Harvard-trained president, certain cultural differences confound the absorption and reaction responses to various types of management decision and implementation of strategic plans for preventing Ebola.

This paper investigates the determinations and resilience of the local people, and determines whether a particular type of leadership can provide nurturing ground for a predictive model, applicable to disaster resilience [7]. It begins with a rationale for the study and declares the need to answer the overarching research question for this study: "What character traits or quality of society was on display in Liberia during the Ebola crises? Next, it summarizes relevant literature on Liberia's unstable past for an understanding of the research context before presenting a justification for the research method. That is followed by some discussions of the results before concluding by suggesting a model that links global healthcare strategy and national government commitment to the behavior of citizens during disasters emergencies.

\section{Literature Review}

Resilience-as a concept-appears in a large number of disciplines, presenting numerous definitions. Not only do these definitions emphasize different elements or attributes of resilience but also speak in a general way to the 'continued ability of a person, group, or system to adapt to stress - any sort of disturbance-so that it may continue to function, or quickly recover its ability to function, during and after stress' [1]. Resilience has also been defined as the capacity of an entity - such as a person, an institution, or a system-to withstand sudden, unexpected shocks, and (ideally) to be capable of recovering quickly afterwards [8]. Resilience, thus, implies both strength and flexibility, where a resilient 
structure would bend, but would be hard to break [21].

Africa's oldest republic, similar in size to Ohio State was formed when the American Colonization Society (ACS) purchased a 50-mile stretch land from 6 indigenous tribal chieftains for $\$ 100,000$ to provide home for freed US slaves [9]. Now a Christian state on the West coast of Africa (mainly Baptist, Methodist, Presbyterian, Protestant Episcopal, Lutheran, Roman Catholic and Seventh Day Adventist). Liberia has many Muslims and tribal religions are practiced in some rural areas. Though enriched with iron ore, timber, diamonds, gold, and hydropower, $80 \%$ of the 2.5 million inhabitants consisting of 28 tribes, reside in the capital city [14].

Liberians started to prove resilience when political upheavals began in 1980s, followed by a brutal 14-year civil war (1989-2003) resulting into a steep decline in the living standards of Liberians, including education and health infrastructure. After successfully contesting the 2005 presidential elections, the Harvard educated Mrs. Ellen JohnsonSirleaf was inauguration on January 16, 2006 and became the first female President in an African State-reelected in 2011.

During the Ebola crises, she strived to lead a government considered an operational organizationseen as an entity that offered predictable, dependable, capable and adaptable action in support of people at risk of, or affected by, outbreaks and emergencies, in ways that strengthen local and national capabilities [27]. An operational organization needs to be [28]:

- present in outbreaks and emergencies - at local levels, and nationally;

- capable of leading, coordinating and implementing key public health functions;

- equipped with adequate capacity to support implementation of these functions;

- ready to engage quickly and openly with other actors for health; and

- consistent in reflecting humanitarian principles, including impartiality.

Governments dealing with disaster must factor in socio-organizational conditions of all citizensleaving no divide between various stakeholders [6] [20].

\subsection{Ebola Outbreak}

CDC (2016) defines Ebola-previously known as Ebola hemorrhagic fever-as a rare and deadly disease caused by infection with one of the Ebola virus species resulting to disease in humans and nonhuman primates (monkeys, gorillas, and chimpanzees). First discovered in 1976 near the Ebola River (in Democratic Republic of Congo), the disease is caused by infection with a virus of the family Filoviridae, genus Ebolavirus named by CDC [3].

The latest outbreak began when Emile Ouamouno (a 2-year old Guinean) lost her bottle to Ebola on 28 December 2013. Despite the cancellation of Liberia's $167^{\text {th }}$ Independence Day celebrations and a ban on international flights to Liberia, the disease set off a worldwide epidemic risking the lives of 232,222,273 in West Africa and an additional $491,108,421$ in the USA and Central Europe as well as the death of more than 11,300 people (see Table 1). It also resulted to the mobilization of a multibillion dollar global response by WHO in 2015 [10].

Table 1 shows Liberia amongst six countries that recently experienced widespread transmission but were able to transition and declared free of Ebola virus transmission-except Sierra Leone where a new confirmed case was identified in 2016 [4]. WHO requires that such country remains free of Ebola virus transmission after 42 days (two incubation periods) had passed since the last Ebola patient tested negative.

\begin{tabular}{|c|c|c|c|c|c|}
\hline \multirow{2}{*}{ Country } & \multirow{2}{*}{$\begin{array}{l}\text { Declared } \\
\text { EBOLA } \\
\text { Free }\end{array}$} & \multirow{2}{*}{$\begin{array}{l}\text { Population } \\
\text { Dec-2014 }\end{array}$} & \multicolumn{3}{|c|}{ Number of Cases } \\
\hline & & & Suspected & Confirmed & Deaths \\
\hline $\begin{array}{lll}\begin{array}{l}\text { Sierra } \\
\text { Africa }\end{array} & \text { Leone, } & \text { W. }\end{array}$ & \begin{tabular}{|l|} 
To be \\
Determined
\end{tabular} & $6,315,627$ & 14,124 & 8,706 & 3,956 \\
\hline Liberia, West Africa & $1-14-2016$ & $4,396,554$ & 10,678 & 3,163 & 4,810 \\
\hline Guinea, W. Africa & 12-29-2015 & $12,275,527$ & 3,814 & 3,358 & 2,544 \\
\hline Nigeria, W. Africa & \begin{tabular}{|l|}
$10-29-2014$ \\
\end{tabular} & $177,475,986$ & 20 & 19 & 8 \\
\hline Mali, W. Africa & 1-18-2015 & $17,086,022$ & 8 & 7 & 6 \\
\hline USA, N. America & N/A & $318,857,056$ & 4 & 4 & 1 \\
\hline Senegal, W. Africa & \begin{tabular}{|l|}
$10-17-2014$ \\
\end{tabular} & $14,672,557$ & 1 & 1 & 0 \\
\hline Spain, C. Europe & N/A & $46,404,602$ & 1 & 1 & 0 \\
\hline Italy, C. Europe & N/A & $61,336,387$ & 1 & 1 & 0 \\
\hline UK, C. Europe & N/A & $64,510,376$ & 1 & 1 & 0 \\
\hline Totals & & $723,330,694$ & 28,652 & 19,261 & 11,325 \\
\hline
\end{tabular}

Table 1: Countries with Confirmed EBOLA Cases \& Deaths as of June, 2016 [7]; National Populations from (http://data.worldbank.org/indicator/ SP.POP.TOTL)

\subsection{Healthcare Infrastructure}

Healthcare infrastructure is "ensuring wellcoordinated, high-quality health care that requires the establishment of a supportive health information system" [15]. The conditions for a high-performance health systems include a well-distributed workforce, information systems for data collection, quality improvement analysis, and clinical communication support, as well as the organizational capacity to support culturally competent services and ongoing improvement efforts [23]. Health authorities in most sub-Sahara countries do very little to promote health 
care delivery systems designed to support community-based resources.

Many considered the Ebola crises a window of opportunity for West African governments to not only reform healthcare infrastructure and other institutional structures, but also establish longstanding policies with WHO for better healthcare systems in Sub Sahara Africa. Similarly, a UN high level panel on global response to Ebola observed that inadequate understanding of the cultural context and poorly designed messaging undermined the response at the community level [29]. The panel also recommendation that Governments in developing countries strengthen and streamline their community engagement and promote local ownership and trust. Their report demanded evidence of the following [29]:

- National authorities and UN partners support the development and use of national social science research capacities, along with an international network of social scientists capable of mobilizing during a crisis period;

- Principles of effective community engagement are featured in all training program for national and international responders.

- National authorities and partners draw on the potential for South-South cooperation in this field.

- Communication strategies are developed with due consideration given to the cultural context.

Healthcare systems also represent true interpretation of authorities' performance in key functions of the national development process [9]. While some may describe the healthcare system in Liberia as self-managed care [22] the lack of a modern healthcare infrastructure contributed to a lack of information support to provide the basis for continuity in patient records and clinician communication at a time of medical need [5][19].

Public health lacks appreciation in many developing countries for improvement in the knowledge of existing human resources. Evidence from Western countries show that investing in community health workers leads to a sustainable success in virus containment [14][23]. Like most developing countries, Liberia has very high unemployment rates, along with a substantial supply of educated people residing in the West, leaving government to scramble for qualified people when crises hit.

In a report presented at the 59th World Health Assembly, the director general noted that reform of WHO's work in health emergency management recognized the special importance of rapid, accurate and objective assessments of risks of potentially high consequences [34]. A program was recently initiated, under the Executive Director, to do on-the-ground assessment when notified of a high threat pathogen (for example, human-to-human transmission of a novel influenza virus), clusters of unexplained deaths in high-vulnerability/low-capacity settings, and other events deemed appropriate at the discretion of the Director-General [31].

The availability and assignment of a culturally competent health care workforce has significant advantages for access to care [12], particularly in developing countries and especially within the most vulnerable populations-low-income and uninsured or underinsured population [2].

A WHO panel recommended the implementation of complementing health systems with development programming [29]. They noted that a strong health systems can be undermined by wider developmental challenges. Several interlocutors identified inadequate water and sanitation, energy, communications, transportation and road networks as major obstacles to improving health services. The Panel also recommends greater complementarity of development efforts with a view to supporting strengthened health systems in developing countries, particularly in rural communities where access to healthcare is the most limited [31]. They also recommended that WHO works closely with development actors to ensure development programming supports health systems and help to improve universal and equitable access to quality healthcare [29].

At the G7 Ise-Shima Summit, G7 leaders, committed to take the following concrete actions for advancing global health and dealing with public health emergencies [10]:

- In addition to its wider reform agenda, urge and support the WHO to implement its reforms for outbreaks and health emergencies, in a timely manner, recognizing also its resource needs, with the understanding that the WHO should continue to play the central role in global public health crisis preparedness and response.

- Welcome the reform of the WHO including to, (i) establish one single approach for outbreaks and health emergencies, with one clear line of authority among all levels of WHO and ultimate accountability with the Director General as crystalized in the One WHO approach across three levels of the Organization, (ii) strengthen capacity and human resources at all levels, and (iii) install an independent mechanism to oversee and monitor the WHO's performance on outbreaks and health emergencies. 
- Recognize that an operationally robust and technically competent WHO is crucial for supporting countries.

Some recommendations for achieving national, systematic and clinical culture competencies from literature are as follows [17]:

I. National cultural competence focus on promoting information dissimilation by national leadership during early stages of health emergencies for developing countries:

- Programs that advance information dissimilation should be encouraged and existing programs should be strengthened in order to develop a cadre of information distribution through academia, government, and private institutions.

- National governments should make it a priority to invest in and promote emergency planning within the healthcare infrastructure.

- Local leadership should be formally or informally involved in deadly disease prevention's planning and quality improvement meetings, whether as part of the local healthcare board or as part of focus groups.

II. Systemic cultural competence recommendations focus on eliminating systemic or institutional barriers to planning for emergencies and improving the health care system's ability to monitor and improve the quality of information about disease crisis [19]:

- Health professionals at county and regional levels should play a significant role warning local population about deadly diseases at a very early stage. Their local influences and ability to interpreter healthcare services, such as remote telephone or simultaneous interpretation, should be used in settings with fewer Ebola patients or with limited financial or human resources.

- Key health information should reflect the appropriate level of health literacy, language proficiency, and cultural norms for the local populations being served. This includes signage, specific programs for health promotion and deadly disease prevention, health education materials, pre- and post-procedure instructions, informed-consent forms, and advanced directives.

- International partners, including USA and Europe, should require systemic cultural competence interventions, involving ethnic data collection and use of local interpreter services) as part of their assistance to national dealing with Ebola.

III. Clinical cultural competence recommendations involves enhancing health professionals' awareness of cultural issues and health beliefs while providing assistance to elicit, negotiate, and manage information about deadly disease [21]:

- Doctors and nurses should recognize various cultural impediments in preventing deadly diseases such as Ebola.

- International clinical staff should enforce equivalent requirements mandating the provision of international standards for healing patients of deadly diseases. Their employers (usually international institutions) should be held accountable for sub-standard services they provide that may prolong deadly diseases.

- Researchers and mangers should identify tools to detect medical errors that result from lack of systemic cultural competence, including those stemming from language barriers. This may involve allow a patent to take a prescribed medication incorrectly; misunderstanding health education materials, instructions, or signage or even inappropriately preparing for a diagnostic, resulting in postponement or delay; and misunderstanding the benefits and risks of procedures requiring informed consent.

- Government of developing countries that receive WHO support should collect data on ethnicity, and language preference for all beneficiaries, members, and clinical encounters to facilitate the monitoring of disparities, the reporting of quality data, and the implementation of initiatives to prevent deadly diseases like Ebola.

\section{Research Method}

Literature shows how research in emergency situations presents many challenges beyond those normally encountered by social scientists [14]. Precautions from Ebola affected the methodological side of our research process. Data from our fieldwork have good validity and reliability, despite taking necessary precaution for safety within a very lifethreatening context. Certain methodological flexibility involving two major components were applied to the survey. The sampling process and the data collection were completed using telephone interviews as the mode of data collection.

Literature review was also structured around questions likely to be of interest to healthcare policies in developing countries researchers, and whether healthcare infrastructure would be a feasible and affordable venture for preventing another deadly disease in the future [11][25]. Literature on the Liberian civil war and its developed path were reviewed for important theoretical and empirical contributions relating to resilience. Computer 
searches resulted from the following keywords: Liberia, Ebola epidemics, civil war, government strategic decisions, disaster management, natural disaster, and international partnerships for crisis prevention. Analysis of these papers provided useful insights that resulted into the following main research questions - meant to aid the creation and accumulation of knowledge in national healthcare infrastructure for developing countries:

1) How can the known input, process, and outcome of Ebola outbreak in Liberia support people facing similar outbreaks elsewhere?

2) How well did the Liberian government manage the Ebola crisis?

3) Did the actions of local population contribute to Ebola spread/cessation?

\subsection{Data Collection}

Primary data was collected through semi-structure interview, via telephone, with people who lived in Liberia during the recent outbreak of Ebola in Liberia, including a number of Americans and Europeans who visited Liberia during this period. All telephone calls were made between January 2015 and December 2015. Telephone interview was considered the best data collection strategy during and immediately after the outbreak of a deadly disease as this offered the following advantages:

- $\quad$ quick distribution and response cycle;

- relatively low cost (cheaper than flying to a neighboring country or distributing laptops to participants;

- accurate recollection of details; and

- no risks of the researcher contacting or being a potential carrier of the disease.

Prior to the telephone interviews, the questionnaire was pre-tested among several Liberians living in USA and Europe who had a reasonable good understanding of the healthcare delivery systems in Liberia. At the end of each individual interview it was indicated that additional analysis would be undertaken, especially to assess the quality of data collected in the survey. Respondents were also asked whether they were happy to give permission to link their answers with the official international reports about the Ebola crisis based on records held by WHO and CDC. Everyone gave consent and encouraged their neighbors and friends who were experiencing similar situation in Liberia to participate in the research.

As a result, few adjustments were made to the questionnaire to ensure respondents would have a deeper understanding of the research objectives. Respondents were allowed extra time towards the end of the telephone interview to add additional topic of relevance to the research objectives.

\begin{tabular}{|l|l|l|}
\hline Gender & Percent & Count \\
\hline Male & $35 \%$ & 21 \\
\hline Female & $65 \%$ & 39 \\
\hline Age Range of Participants & Percent & Count \\
\hline $15-21$ & $8 \%$ & 5 \\
\hline $22-30$ & $12 \%$ & 7 \\
\hline $31-40$ & $30 \%$ & 18 \\
\hline $41-50$ & $17 \%$ & 10 \\
\hline Above 50 & $33 \%$ & 20 \\
\hline Which part of the Country do you live normally? & Percent & Count \\
\hline Central Monrovia & $27 \%$ & 16 \\
\hline Greater Monrovia & $50 \%$ & 30 \\
\hline Other big cities in Liberia & $17 \%$ & 10 \\
\hline Small towns in Liberia & $7 \%$ & 4 \\
\hline Highest Educational Level & Percent & Count \\
\hline University Graduate & $17 \%$ & 10 \\
\hline University Student & $18 \%$ & 11 \\
\hline High School Graduate & $42 \%$ & 25 \\
\hline Elementary School Graduate & $13 \%$ & 8 \\
\hline Never went to School & $10 \%$ & 6 \\
\hline Questions About Participants Perception of Ebola Management & Percentage & Count \\
\hline Are you a member of the Ebola Control Management Team? & $15 \%$ & 9 \\
\hline $\begin{array}{l}\text { Have you taken care of a relative or friend who may have } \\
\text { Ebola symptom? }\end{array}$ & $83 \%$ & 50 \\
\hline Should the borders have been closed to prevent the Ebola crisis & $78 \%$ & 47 \\
\hline $\begin{array}{l}\text { Did the Government make the right decision at the beginning } \\
\text { of Ebola? }\end{array}$ & $22 \%$ & 13 \\
\hline $\begin{array}{l}\text { Did the Government make the right decision when people were } \\
\text { dying? }\end{array}$ & $67 \%$ & 40 \\
\hline $\begin{array}{l}\text { Did the Ebola end as a result of good decisions by the } \\
\text { Government? }\end{array}$ & $97 \%$ & 58 \\
\hline $\begin{array}{l}\text { Should people be allow to bury family members who died from } \\
\text { Ebola? }\end{array}$ & $18 \%$ & 11 \\
\hline Did everybody do their best to prevent the spread of Ebola? & $38 \%$ & 23 \\
\hline $\begin{array}{l}\text { Do you trust this government to prevent another Ebola } \\
\text { outbreak? }\end{array}$ & $75 \%$ & 45 \\
\hline $\begin{array}{l}\text { Are you presently engaged in farming to sustain yourself } \\
\text { during the Ebola outbreak? }\end{array}$ & $65 \%$ & 39 \\
\hline $\begin{array}{l}\text { Did the national government communicate Ebola prevention } \\
\text { properly? }\end{array}$ & $5 \%$ & 3 \\
\hline $\begin{array}{l}\text { Were competent health workers available in your area to } \\
\text { prevent Ebola? }\end{array}$ & $30 \%$ & 18 \\
\hline $\begin{array}{l}\text { Were the equipment good enough in your area to prevent } \\
\text { Ebola? }\end{array}$ & $7 \%$ & 4 \\
\hline $\begin{array}{l}\text { Is the International community doing enough to safe Liberians } \\
\text { rom Ebola? }\end{array}$ & $15 \%$ & 9 \\
\hline $\begin{array}{l}\text { Is the International community doing enough to prevent Ebola } \\
\text { from spreading outside the Liberian border? }\end{array}$ & $89 \%$ \\
\hline
\end{tabular}

Table 2: Partial data from Telephone Survey

\subsection{Sample Data}

The demographic data of the sample were collected by asking the respondents their gender, age, education level, organization level and their amount of work experience in the field (see Table 2). The average age of the respondents was 45 years old, with the standard deviation of 10 . Respondents` age varied from 19 to 68 years. Male respondents made up 35\% of the sample and $65 \%$ were female, as is characteristic of the general Liberian population. The highest educational level attained was, $17 \%$ university, $18 \%$ college level, $42 \%$ high school, and $13 \%$ elementary school level, while $10 \%$ of the respondents did not have any formal education. $45 \%$ of the respondents had no role in the Ebola control process, $83 \%$ had personal commitment to look after 
family member of close friend but no official government designated status, $77 \%$ of respondents lived in Monrovia or its suburbs while $17 \%$ lived in other big cities but $7 \%$ lives in small rural towns in Liberia.

\section{Discussion}

Like most developing countries Liberia's response to Ebola was greatly hampered by the lack of formal instrument for predicting chemical hazard, natural disasters and deadly diseases - an essential part of any basic healthcare infrastructure that would provide a potentially endless as well as essential resources for societal characteristics that can promote or inhibit resilience [21]. The following comments from interviewees confirm the recommendations in the advisory group's report for WHO reform [30]. "We do not have the type of leadership required to support our very dedicated nurses and other emergency workers when the health of millions of Liberians is threatened by Ebola outbreak". A young college student claimed: "It is rumored that International community has given billions of dollars to Liberia to help our plight. But we do not see a single report indicating specific program of work, or a budget or operations support system, or a set of management processes within the local community to ease our pain. Yet Liberians have remain very flexible and adaptable to the increasing danger simply because of the multi-faceted nature of our resistance to natural and disease emergencies." Another interviewee expressed: "Ebola started 8 months ago but we are yet to true analysis of stakeholders on the ground, who are working with local leaders and different health cluster partners to build a dedicated cluster capacities, and ensure the integration of the capacities of Health Cluster partners in emergency operations, and avoid wastages. How can we avoid Ebola elsewhere if the International community does not undertake a stakeholder analysis of local partners?"

All three comments above suggest a situation that requires systemic healthcare infrastructure with established procedures that prevents common challenges of interactions among factors and leads to the dynamism of future changes to global public health. Such systems will contribute to a global early warning function and global health emergency workforces-something that aligns with WHO's plans to define and promote acceptance of common professional standards, and build a robust capacity for systematized information management as part of its work on supporting health workforces and technical networks [30].

\subsection{Standards for Resilient Society}

Advances in our understanding of disaster resilience in Western society are yet to match the increasing need for leadership in developing countries during disaster situations-quite often a lot more deadly with much less infrastructures available to manage the disaster and safe lives [7][25]. Resilience is quite often universal in meaning but may be unique in applications. Attempts to apply resilience that requires doing anything to stay alive may lead the resilient person to taking desperate actions. This interviewee was present in 2015 when residents of Bushrod Island in Monrovia refused to allow care workers into their township to provide medical assistance for patients or even collect bodies of Ebola victims. "This is not New York or London or Rome where the residents have many options to choose from during emergency situation. In Liberia, we can only make a onetime judgment, unable to change what happens after the fact." Unlike residents of Dallas or Madrid (where patients had also been tested positive with the Ebola virus) Liberians lived in a resilient society with no control over how things play out once they have taken the initial actions.

One interviewee explained "The series of failures by United Nations and CDC during the beginning of Ebola demonstrates that the entire world remains illprepared to address any threat posed by deadly epidemics. The Liberian government had not even invested in basic surveillance capacities allowing the Ebola virus to initially spread undetected for several months". These vulnerable people felt the need to innovate their approach to the unstructured medical process by enhancing their resilience. This proves that different kinds of shocks and stresses within an already bad healthcare system can combine to bring new problems or exacerbate existing problems in unforeseen ways. Liberia was most vulnerable in 2014 to medical problems and lacked the appropriate resources needed for structured processes of innovation to deliver scientifically robust solutions for reducing risk for Ebola spread [24].

The local population showed changes in behavior and demonstrated appreciation after President Obama sent military personnel, followed immediately by large volumes of resources from the international community to finance the Ebola response. Household incomes had suffered greatly as a result of loss of wage jobs and self-employment activities in 2014. Nearly half of our interviewees confirmed Liberian household heads who were working in the first half 
of 2014 reported being out of work, with those job losses concentrated among urban, private-sector wage-earners. Government workers also faced furlough. As per gender effect of Ebola and jobs in Liberia, 60 percent of women versus 40 percent of men working in early 2014, had ceased to work by December 2014.

Radical learning is achieved through direct interaction with people around the leader and engaging in group activities (including town hall meetings, conferences, fairs, sports stadiums, etc.) where the leader explores new ideas and approaches related to his/her role to get things done immediately. One local leader lamented: "We are not surprised that President Sirleaf did not know how to handle this type of crises. All her cabinet members were out of the country when we were suffering here during the previous crises." This represented opinions from many in Liberia who assumed the government had learned from previous national crisis - establishment of pre-disaster ties and common communication tools with NGOs-but that proved futile. A government official defended the leadership position: "This leadership was aware that nearly every previous knowledge about crisis management had to be abandoned in favor of new knowledge and better outcome. Remember all our old knowledge were obtained from dealing with a different type of crisiscivil war, and government coup."

This is supported by the UN's high-level panel on the Global Response to Health Crises report that acknowledged new and dangerous pathogens can emerge in any country in the world. The report warned that "poor living conditions mean developing countries are particularly vulnerable to impact of communicable disease outbreaks. Inadequate sanitation can accelerate disease spread and weak health systems undermine the capacities to respond" [29].

Literature also suggest that crisis and leadership are intertwined since both concepts have a nature to complement one another [6]. One Liberian living abroad concluded "The Ebola crises as an event, was not neatly delineated, but rather of high uncertainty. Liberians-both home and abroad-looked to the country leaders for safety and direction. Mrs. Sirleaf is not only responsible for responding to threats and uncertainties facing all citizens but also has the challenge of bringing the situation to a point where international investors and Liberian citizens abroad would feel comfortable to return to Liberia and help."

\subsection{Analysis of Different Dimensions}

World Bank (2006) confirmed stagnation in the national economic for 2014 resulted from low diesel sales, an 11 percent contraction in money supply through 2014, and a 30 percent slump in imports By early 2015 government effort led to decline in new cases of Ebola. These were also results of domestic aversion behavior abating along with international aversion behavior, which was much slower to respond. By late 2014, income shock and higher prices for key staples have resulted in widespread food insecurity. More than ninety percent of households interviewed have cited food insecurity as an issue in the survey [29].

Liberia's mining sector remained resilient during the Ebola outbreak, although investments to expand capacity remain on hold. Another challenge was posed by the slowdowns in Chinese and in European economics, leading to significant decline in iron ore prices-falling to about half in 2015. The resilience of manual workers in the rubber farms of Liberia kept the country's second largest export faring a little better-falling by only 30 percent.

As Liberians struggled through a very deteriorating economic, the leadership had to respond with the appropriate approach, aware that it was resulting to several thousand deaths. Resilience entails activities that are meant to be focused in progressive stages. It begins with i) preventive measures, followed by ii) mitigation and followed closely by iii) critical decision making by leadership, and then finally iv) the eventual push towards a return to normalcy.

"We are very happy for the private-sector construction that is taking place as a result of the Ebola-related construction. As this type of construction contract winds down, there is a reduction of domestic cement production. Two Chinese contractors resumed work on World Bank roads projects in December 2014, in addition to many new construction in preparations for reopening of schools in the spring of 2015."

Resilient leadership in such a situation requires a contradictory blend of talent for clear-eyed analysis and the ability to take bold action-something shown by President Barrack Obama in sending American soldiers to Liberia when nearly every airline concluded it wasn't safe to fly into Liberia for fear of employees contracting this deadly disease. Like most national crises, Ebola was accompanied by a high degree of uncertainty. Thus, managing Ebola preparation and recovery proved impossible for the Liberian government. The Liberian government demonstrated resilience through their leadershipaware that citizens expected an outcome that would 
keep them alive. It was this type of resilience in the gaze of epidemic that defined the true devastation of Ebola in Liberia.

\subsection{Society and Cultural Ties}

While the outside world struggled to comprehend any perceived benefit of physical interactions (handshakes, hugging and similar behaviors during the Ebola crisis), Liberians were culturally resilience, regularly examined the benefits in their interactions with others - who could have been infected with the deadly disease-but only if they believed that participating in the cultural exchange process would bring them little satisfactory rewards during a time of total grim in the local society.

"Because of Ebola control, we are expected to live as individuals. We are not allowed to touch our family and friends by hugging and handshakes. Ebola has also forced us to move from big cities into rural villages, and work as farmers." Despite this interviewee claims, harvests for spring 2015 was significantly plumage. Eighty percent of participants blamed the reduction in crops to reduced labor sharing, leading to further reductions in food supply for 2015 .

"As Ebola spreads throughout the country, the rural community has become increasingly uncertain with constrained resources. This has forced local leaders to result to autonomous innovations which should be flexible and instinct-driven, that will allow us to function through a variety of disturbances in this challenging and very deadly situation." This comment from a local community leader confirms conclusions from literature that operational effectiveness during outbreaks and emergencies requires leadership positioning themselves as operational organization while maintaining leadership in technical expertise.

"Our leadership is valuable to solving this problem because our community is on the front-line of the Ebola outbreak. We are responsible and accountable for issuing appropriate alerts and responding to a suspected Ebola cases. We need health systems and architecture that contain foundational capabilities for effective preparedness and response." This comment, also from a local community leader, confirms literature about the inadequate implementation of national obligations under the weak health systems, governance challenges, and poor engagement with communities hampered the ability of national authorities to stem the spread of the virus [17][29].

Similar comments from Interviewees support literature that leaders of global healthcare (WHO) should proactively define and promote acceptance of common professional standards on health interventions, sharing information and handling personal health data. Investing in worldwide Health Systems would build robust capacity for systematized information management and protocols to enable health data from multiple sources to be shared [33]. Implementation of a sustainable emergency system, procedures and capacity to develop and update resilience to deadly diseases should be an ongoing objective of WHO, including rapid availability of an interactive, accessible IS repository for Ebola management.

Many Liberians used mobile technology to spread information about government policies and plans for actions relating to suspected Ebola cases and Ebola control team arrivals into different villages. "It would have been in national interest to take advantage of existing mobile technology (spread throughout the remote districts of Liberia) to deliver a strong public health message to the Liberians. Isn't it mindblowing when people report the lack of communication technology between Monrovia and Ganta (around 200 miles apart) yet family members in USA (more than 6000 miles away) were practically in constant communications-via mobile technology-immediately after a family member showed symptom of serious illness? These comments demonstrate that in the absence of a well-functioning healthcare infrastructure, any country can be exposed to a catastrophe far more destructive than national security, as experienced by Liberia in 2014.

Resilience in such environment allows the institutionalization of political agendas when budgeting for national healthcare and avoiding improper prioritizations, which may increase the risk of deadly disease spread, lower the morale of health care workers, and diminish patients' quality of life [5][14]. Resilience in culture meant caring for sick family members - something very central to West African culture. The researcher noticed a wellestablished communications system between groups of Liberians spread around the world, usually as part of similar descendants of past inhabitants of certain families within a specific territory. This is exclusive of other groups within a small territory, and formed by involuntary membership of an inclusive category. All people privileged to the news of a seriously sick family member would usually belong to one tribal group, by reason of being extended families and/or inhabiting the region-sometimes referred to as normative tribalism, and semantically correct to describe it as a form of local-mindedness. Because certain financially influential members of such extended family may now be living in the West, it has become imperative to use mobile technology to 
spread such sick news - thus, improving explain the role of family ties through culture during resilience to a deadly disease.

"Ebola outbreak has not been able to keep our residents away from complementary leisure facilities, and other tourist resources frequently used to meet their needs for home-based tourism. We use friendly attitude-hugs and handshakes at every opportunity - to establish channels of communication with the outside world. Research aligns with these comments that once established, negative reputations are very difficult to change [18][28].

A good strategy for developing a national healthcare infrastructure must have certain essential elements. Such strategy must include standards for effective data sharing.

\section{Research Limitation and Future Research}

This paper uses data from a telephone interview which is a rarely used research method but the justification is the researcher's inability to travel to the research locations during a deadly disease outbreak. While the results of this research may not be generalizable, due to the rare occurrence of Ebola outbreak, they definitely fill a critical gap in the literature and also be applicable in similar contexts. One limitation of this method is the lack of attempt to address the effect of non-relations sampling. Intuitively obtaining information from people who are considered old friends and former colleagues, as well as close contacts of the researcher's family members and their neighbors - all facing life-anddeath situations-making it more likely the survey would produce specific theme-relevant material.

This exploratory study has raised several issues that provide fruitful avenues for future research in the area of disaster resilience in developing countries. First, several contingencies have been identified (stages in decision making process, involvement of local authorities, etc.) as possible explanations for strong resilience during a deadly disease outbreak in developing countries. The study will now be expanded to include longitudinal and participatory research techniques [32] involving local researchers based at the University of Liberia and other partners with NGOs in Monrovia. Future research on the impact of disaster resilience in developing countries will also examine the inclusion of additional constructs.

\section{Conclusions}

To answer our major questions, we have seen how Liberians exhibit resilience, evidencing normal life in the face of adversity. Despite Ebola killing children, women and old people, there was no evidence of any negative effects at the individual, family, community, and cultural levels - contributing to an understanding of resilience processes within non-Western populations. Although some general trends in disaster resilience may extend beyond good leadership /government, resilience here was strongly influenced by culture.

For resilience research, social competence has generally been operationalized on the basis of observable, behavioral criteria, with assessments based on achievements [8] [13]. This paper aligns with literature that demonstrate the importance of ensuring resilience processes are informed-and where possible set - by those who must change [7]. Additionally, the paper has aligned with the unfortunate events in Liberian history, especially the Ebola outbreak and argues for seeing communities not merely as victims of disaster but also as agents of resilience.

By early 2015, the international community-led by USA - had to send both military and medical personnel to help Liberian government control Ebola spread. Through this strategy, the Liberian leadership demonstrated a certain type of resilience, being flexible in decision making and operations, adaptability to disaster conditions, and effective communication with other stakeholders and the public as the most valuable resource required for leading a developing country through the outbreak of a deadly disease.

The second implication of this finding is the protective versus vulnerability effects across the populations studied. For instance, while the local population was frightened and intentionally still indoors-being protective with regard to disruptive behaviors during a medical crisis, the society was functioning as a vulnerability factor for other domains and therefore being described as public disobedience. For an economically disadvantaged citizen, facing Ebola, on the other hand, increasing freedom to express their frustration at the system was a desirable outcome.

Apart from public demonstration, caring for former family member was another variable that was found to be a vulnerability factor [14]. This variable, too, has been previously shown to serve protective functions, in experimental as well as longitudinal investigations [2]. 
Previous theoretical and empirical works in the area have contained cautionary statements on the use of terms such as "invulnerable" and "resilient." For instance, it has often been noted that resilience is not necessarily continuous over time but is, instead, interspersed with setbacks under certain circumstances [8][9][26]. Evidence that resilient population in this study were significantly more depressed and anxious than were government officials suggests that while the type of problems developed may vary, some type of difficulties may inevitably be associated with a population gazing at Ebola.

\section{References}

List and number all bibliographical references in 9-point Times, single-spaced, at the end of your paper. Alphabetize by the last name of the first author. When referenced in the text, enclose the citation number in square brackets, for example [1]. Where appropriate, include the name(s) of editors of referenced books.

[1] Bahadur, A. \& Doczi, J. (2016). Unlocking resilience through autonomous innovation. (www.odi. org/sites/odi.org.uk/files/odiassets/publications-opinio n-files/10245.pdf).

[2] Callaway, D., Bobko, J., Smith, E.R., Shapiro, G., McKay, S., Anderson, K., Sarani, B. (2016). Building community resilience to dynamic mass casualty incidents: A multiagency white paper in support of the first care provider. Journal of Trauma and Acute Care Surgery. Vol.80, Iss-4, pp.665-669.

[3] CDC (Centers for Disease Control and Prevention) (2016). About Ebola Virus Disease. Downloaded in February 2016 from (http://www.cdc.gov/vhf/ebola/ about.html)

[4] CDC (Centers for Disease Control and Prevention) (2016). 2014 Ebola Outbreak in West Africa - Case Counts. Downloaded in February 2016 from (http://www.cdc.gov/vhf/ebola/outbreaks/2014west-africa/ case-counts.html)

[5] Currie, WL \& Guah, MW (2007) 'Conflicting Institutional Logics: A National Programme for IT in the Organizational Field of Healthcare'. Journal of Information Technology, 22(3), 235-247.

[6] Demiroz, F. \& Kapucu, N. (2012). The Role of Leadership in Managing Emergencies and Disasters, European Journal of Economic and Political Studies, 5(1), 91-101.

[7] Dobel, JP (2010). Mission integrity in disaster management. Public Administration Review, 70 (Suppl. s1), s182-s184.
[8] Frerks, G.E. (2015). 'Resilience. A Review of the Literature: Queries Beyond the Promise'. In Irna van der Molen \& Nora Stel (Eds.), Conflict and Environment in North Lebanon, Vulnerability and resilience from a multi-disciplinary perspective. (pp. 43-54)

[9] Frerks, G., Warner, J. \& Weijs, B. (2011). The Politics of Vulnerability and Resilience.Paper written for the Netherlands US Crisis Research Network. (http://www.scielo.br/pdf/asoc/v14n2/08.pdf).

[10] G7 Ise-Shima (2016). Vision for Global Health. Downloaded in August 2016.

http://www.mofa.go.jp/mofaj/files/000160273.pdf

[11] Gates, B. (2015, March 18). The Next Epidemic

- Lessons from Ebola. N Engl J Med, 372, p. 13811384.

[12] Guah, M.W. (2011) 'Why doesn't Information Systems Vision exists in the Healthcare Sector?' Chapter in Ethical Issues and Security Monitoring Trends in Global Healthcare: Technological Advancements. Edited by Brown, S.A. \& Brown, M., 207-217.

[13] Haer, R. \& Becher, I. (2012). A methodological note on quantitative field research in conflict zones: get your hands dirty. International Journal of Social Research Methodology, 15(1), 1-13.

[14] Ighobor, K. (2015). Billions now required to save depleted healthcare systems: Ebola's most affected countries lobby for funding for hospital infrastructure, Africa Renewal Magazine, August2015, page- 14 .

[15] Institute of Medicine (2010). Future directions for the National Healthcare Quality and Disparities Reports. Institute of Medicine Board of Health Care Services. Washington, DC: National Academies Press.

[16] Kapucu, N. \& Van Wart, M. (2006). "The Evolving Role of the Public Sector in Managing Extreme Events: Lessons Learned", Administration \& Society 38 (3), 279-308.

[17] Médecins Sans Frontières. (2015). Pushed to the Limit and Beyond: A year into the largest ever Ebola outbreak. Downloaded in January 2016 from https://www.doctorswithoutborders.org/sites/usa/files /msf143061.pdf

[18] Menéndez, C., Lucas, A., et al. (2015). Ebola crisis: the unequal impact on women and children's health. Lancet. http://dx.doi.org/10.1016/S2214109X(15)70009-4

[19] Moon, S., Sridhar, D., et al. (2015). Will Ebola change the game? Ten essential reforms before the next pandemic. The report of the Harvard-LSHTM Independent Panel on the Global Response to Ebola. Lancet, $\quad 386$ : 2204-21. http://dx.doi.org/10.1016/S0140 -6736(15)00946-0 
[20] NAM Commission on a Global Health Risk Framework for the Future (Jan 2016: The Neglected Dimension of Global Security: A Framework to Counter Infectious Disease. Crises.) http://nam.edu/ wp-content/uploads/2016/01/Neglected-Dimensionof-Global-Security.pdf

[21] Noltemeyer, AL \& Bush, KR (2013). Adversity and resilience: A synthesis of international research. School Psychology International, 34(5), pp.474-487.

[22] Raghupathi, V. \& Raghupathi, W. (2015). An Empirical Analysis of the Status of Country-level Public Health. Journal of Health Policy and Technology, 4(2), 156-167.

[23] Roe, E \& Schulman P.R. (2015). Comparing Emergency Response Infrastructure to Other Critical Infrastructures in the California Bay-Delta of the United States: A Research Note on InterInfrastructural Differences in Reliability Management, Journal of Contingencies \& Crisis Management, 23(4), 193-200.

[24] Rollins, L. (2014). New Ebola hospital in Liberia overwhelmed by patients. Access in June 2016 @ http://wtvr.com/2014/09/23/new-ebolahospital-in-liberia-overwhelmed-by-patients/.

[25] Save the Children. (2015). A Wake-Up Call: Lessons from Ebola for the world's health systems. London, United Kingdom: Save the Children.

[26] Siedner, M.J., Gostin, L.O., et al. (2015). Strengthening the Detection of and Early Response to Public Health Emergencies: Lessons from the West African Ebola Epidemic. PLoS Med 12(3).

[27] Summers, A. (2014). Challenges in Responding to the Ebola Epidemic - Four Rural Counties, Liberia, August-November 2014. Atlanta, GA, USA: CDC Morbidity and Mortality Weekly Report. Downloaded in January 2016 from http://www.cdc.gov/mmwr/ preview/mmwrhtml/mm6350a5.htm

[28] Tully, C.M., Lambe, T., et al. (2015. Emergency Ebola response: a new approach to the rapid design and development of vaccines against emerging diseases. Lancet Infect Dis http://dx.doi.org/10.1016/S1473-3099(14)71071-0

[29] UN High Level Panel on Global Response on Health Crises (Jan 2016): Protecting Humanity from Future Health Crises. Dowloaded in August 2016. http://www.un.org/News/dh/infocus/HLP/20160205_Final_Report_Global_Response to

Health_Crises.pdf

[30] WHO (2016). Advisory Group on Reform of WHO's Work in Outbreaks and Emergencies 2nd Report. Downloaded in August 2016 from http://who.int/about/who_reform/emergencycapacities/advisory-group/second-report.pdf?ua=1
[31] WHO Health Emergencies Program (2016). Reform of WHO's work in health emergency management. Downloaded in August 2016. http://apps.who.int/gb/ebwha/pdf_files/WHA69/A69 _30-en.pdf

[32] Wright, A.L., Nichols, E., McKechnie, M. \& McCarthy, S. (2013). Combining Crisis Management and Evidence-Based Management: The Queensland Floods as a Teachable Moment, Journal of Management Education, 37(1) 135-160. 